\title{
RESEARCH
}

\section{CHI3L1 results in poor outcome of ovarian cancer by promoting properties of stem-like cells}

\author{
Han-Wei Lin1, Ying-Cheng Chiang², Nai-Yun Sun1, Yu-Li Chen², Chi-Fang Chang², Yi-Jou Tai², Chi-An Chen² and \\ Wen-Fang Cheng $1,2,3$ \\ ${ }^{1}$ Graduate Institute of Oncology, National Taiwan University, Taipei, Taiwan \\ 2Department of Obstetrics and Gynecology, National Taiwan University, Taipei, Taiwan \\ ${ }^{3}$ Graduate Institute of Clinical Medicine, College of Medicine, National Taiwan University, Taipei, Taiwan
}

Correspondence should be addressed to W-F Cheng: wenfangcheng@yahoo.com

\begin{abstract}
The role of chitinase-3-like protein 1 (CHI3L1) in ovarian cancer and the possible mechanisms were elucidated. CHI3L1 is a secreted glycoprotein and associated with inflammation, fibrosis, asthma, extracellular tissue remodeling and solid tumors. Our previous study showed CHI3L1 could be a potential prognostic biomarker for epithelial ovarian cancer and could protect cancer cells from apoptosis. Therefore, clinical data and quantitation of CHI3L1 of ovarian cancer patients, tumor spheroid formation, sidepopulation assays, Aldefluor and apoptotic assays, ELISA, RT-PCR, immunoblotting and animal experiments were performed in two ovarian cancer cells lines, OVCAR3 and CA5171, and their CHI3L1-overexpressing and -knockdown transfectants. High expression of CHI3L1 was associated with poor outcome and chemoresistance in ovarian cancer patients. The mRNA expression of CHI3L1 in CA5171 ovarian cancer stem-like cells was 3-fold higher than in CA5171 parental cells. CHI3L1 promoted the properties of ovarian cancer stem-like cells including generating more and larger tumor spheroids and a higher percentage of $\mathrm{ALDH}^{+}$in tumor cells and promoting resistance to cytotoxic drug-induced apoptosis. CHI3L1 could induce both the Akt (essential) and Erk signaling pathways, and then enhance expression of $\beta$-catenin followed by SOX2, and finally promote tumor spheroid formation and other properties of ovarian cancer stem-like cells. OVCAR3 CHI3L1-overexpressing transfectants were more tumorigenic in vivo, whereas CA5171 CHI3L1-knockdown transfectants were not tumorigenic in vivo. CHI3L1 critically enhances the properties of ovarian cancer stem-like cells. CHI3L1 or CHI3L1-regulated signaling pathways and molecules could be potential therapeutic targets in ovarian cancer.
\end{abstract}

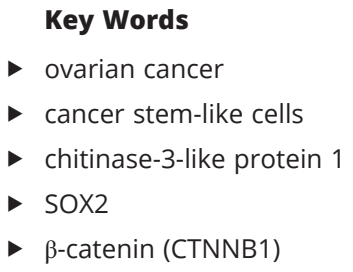

Endocrine-Related Cancer (2019) 26, 73-88

\section{Introduction}

Ovarian carcinoma is the leading cause of death among all gynecologic malignancies, with more than $70 \%$ of women presenting with advanced-stage disease (Cohen et al. 2014). The annual incidence rate of ovarian cancer in the United States was 12.2 per 100,000 and the death rate was 8.2 per 100,000 in 2007 (U.S. Cancer Statistics
Working Group); these rates were respectively 9.12 and 3.09 in Taiwan (Chiang et al. 2013). The poor prognosis for these patients is the result of a lack of symptoms, difficulties in early diagnosis, insufficient accurate tumor markers and deficiency of knowledge about ovarian tumor cell biology (Pinke et al. 2008). The standard 
treatment for ovarian cancer is surgical tumor debulking, followed by platinum-containing chemotherapy (Agarwal \& Kaye 2003, Nagourney et al. 2003). Conventional prognostic parameters for ovarian carcinoma are tumor stage, residual tumor volume after surgery, histologic type, differentiation grade and response to chemotherapy (van der Burg et al. 1988). However, these factors do not present a comprehensive picture of the tumor biology of ovarian cancer and are frequently interrelated. Thus, identifying the molecular pathways of ovarian cancer is extremely important for diagnosis and treatment of this disease.

Increasing evidence supports the hypothesis that a subpopulation of cancer cells with stem cell features lurks within cancers (Crea et al. 2009, Clevers 2011, Visvader 2011, Moncharmont et al. 2012, Pylväs-Eerola et al. 2016). The proportion of these cancer stem-like cells or cancerinitiating cells in tumors is generally less than $2 \%$ (Tang et al. 2007). Compared to other cells, these cancer stemlike cell populations are more tumorigenic, metastatic, invasive, prone to angiogenic switch and resistance to chemotherapy and radiotherapy (Bapat et al. 2005, Wu \& Alman 2008, Crea et al. 2009, Ahmed et al. 2010, Visvader 2011, Moncharmont et al. 2012, Steg et al. 2012). The multipotent cancer stem-like cells with these properties drive histologic heterogeneity within the tumors (Park et al. 2010). The high incidence of disease recurrence may also contribute to the multidrug resistance and multiple histological phenotypes of the multipotency of stem celllike properties (Raghavan et al. 2017). Chitinase-3-like protein 1 (CHI3L1 or YKL-40) is a secreted glycoprotein with a molecular weight of about $40 \mathrm{kDa}$. It is a member of the glycosyl hydrolase 18 family, lacks chitinase activity, and is produced by the various types of cells, including inflammatory cells and cancer cells (Libreros \& Iragavarapu-Charyulu 2015, Wiley et al. 2015). Expression levels of CHI3L1 in serum or tissues positively correlate with various types of cancer, including ovary, lung, breast and brain (Johansen et al. 2004, Park et al. 2010, Ku et al. 2011, Chiang et al. 2015a), and with several inflammatory or autoimmune diseases, including coronary artery disease, diabetes mellitus and rheumatoid arthritis (Kazakova et al. 2013, Hansen et al. 2015, Wiley et al. 2015). CHI3L1 is hypothesized to play a role in cancer cell proliferation, migration, invasion and metastasis. Although CHI3L1 can be a marker associated with a poorer clinical outcome of different tumors, its biologic functions and possible mechanisms of action remain under investigation.

Our previous study identified that ovarian cancerous tissues expressed higher CHI3L1 than ovarian benign and normal tissues (Chiang et al. 2015a). Besides, CHI3L1 was associated with poor prognosis of advanced-stage ovarian cancer patients (Chiang et al. 2015a). To explore the possible biological functions of CHI3L1 in this cancer, we hypothesized that CHI3L1 could promote its cancer stem-like cell properties. We first found that RNA levels of CHI3L1 in CA5171 ovarian cancer stem-like cells were 3-fold higher than those in CA5171 parental cells. Moreover, CA5171 spheroid cells are more chemoresistant and prone to tumorigenesis than their parental cells. CHI3L1 promotes properties of ovarian cancer stem-like cells, including generating larger and more numbers of tumor spheroids, higher percentages of $\mathrm{ALDH}^{+}$tumor cells, and resistance to cytotoxic drug-induced apoptosis. CHI3L1 could induce both of the Akt (essential) and Erk signaling pathways, and then enhances expression of $\beta$-catenin followed by SOX2, and finally promotes tumor spheroid formation and the various properties of ovarian cancer stem-like cells. In vivo, OVCAR3 CHI3L1overexpressing transfectants were more tumorigenic, whereas CA5171 CHI3L1-knockdown transfectants were less tumorigenic. Our findings suggest that CHI3L1 and its related axis (CHI3L1- $\beta$-catenin-SOX2) may provide a promising target for the treatment of ovarian cancer.

\section{Materials and methods}

\section{Patients and specimens}

From 2000 Jan to 2016 Jun, 113 women with advancedstage (stages III and IV) ovarian carcinoma treated in our institute were enrolled. The Institutional Review Board of the hospital approved the study protocol and the patients provided informed signed consent after Jun, 2007. Tissue specimens were collected during surgery, immediately frozen in liquid nitrogen and stored at $-70^{\circ} \mathrm{C}$ until analysis. The characteristics of disease were defined according to the system of International Federation of Gynecology and Obstetrics (FIGO; Prat 2014). The optimal debulking surgery was defined as when the maximum diameter of a residual tumor was $<1 \mathrm{~cm}$. After completion of the primary treatment, history taking, pelvic/rectal examination and regional lymph nodal palpation would be arranged every 3 months for 3 years, and every 6 months thereafter. Recurrence was recorded when tumor marker levels were greater than or equal to twofold the upper limit of normal in two consecutive tests with 2-week intervals, findings of imaging studies and aspiration cytology were abnormal or when there was histological confirmation from a tissue biopsy. The period from completion of the primary 
Table 1 Clinico-pathologic characteristics of the ovarian carcinoma patients $(n=113)$.

\begin{tabular}{l}
\hline Characteristic \\
\hline Age (<50/>50, year-old) \\
Disease status \\
FIGO stage (III/IV, cases) \\
Histology (serous/clear cell/endometrioid/mix, cases) \\
Tumor grade (1/2/3, cases) \\
Debulking surgery (optimal/suboptimal, cases) \\
Biomarker \\
CHI3L1 mRNA expression level (median (range)) \\
Outcome \\
Disease recurrence (yes/no, cases) \\
Disease-related death (yes/no, cases)
\end{tabular}

\begin{tabular}{c}
\hline Patients $(n=113)$ \\
\hline $20 / 93$ \\
$97 / 16$ \\
$85 / 15 / 11 / 2$ \\
$7 / 2 / 104$ \\
$57 / 56$ \\
$7.6(0.00-668.0)$ \\
$86 / 27$ \\
$53 / 60$ \\
\hline
\end{tabular}

FIGO, International Federation of Gynecology and Obstetrics.

treatment until the diagnosis of disease recurrence was defined as disease-free survival (DFS). The time from the diagnosis of the disease until the date of death or last visit was defined as overall survival (OS).

\section{Cancer cell lines}

We used two OVCAR3 and CA5171 ovarian cancer cell lines in our studies. OVCAR3 cells purchased from American Type Culture Collection were maintained in RPMI-1640 medium supplemented with $0.01 \mathrm{mg} / \mathrm{mL}$ bovine insulin and $20 \% \mathrm{FBS}$ and grown at $37^{\circ} \mathrm{C}$ under $5 \% \mathrm{CO}_{2}$ (Chiang et al. 2015b). The molecular authentication of OVCAR3 cell line used in this study was confirmed by STRS analyses as showed in Supplementary Figs 1 and 2 (see section on supplementary data given at the end of this article). The other ovarian cancer cell line, CA5171, established in our lab, was cultured in RPMI-1640 supplemented with 20\% FCS, 50units/mL penicillin/streptomycin, $2 \mathrm{mM}$ L-glutamine, $1 \mathrm{mM}$ sodium pyruvate and $2 \mathrm{mM}$ nonessential amino acids and grown at $37^{\circ} \mathrm{C}$ under $5 \%$ $\mathrm{CO}_{2}$ (Chiang et al. 2015b). The passage numbers of the cells used in the following experiments were from P3 to P5.

\section{Tumor spheroid formation}

To generate tumor spheroids, we seeded OVCAR3, OVCAR3/CHI3L1-C4, OVCAR3/CHI3L1-C9, CA5171, CA5171/shCHI3L1-S1 and CA5171/shCHI3L1-S2 cells under stem cell conditions as follows: serum-free minimal essential media (RPMI-1640) supplemented with $1 \%$ FBS in 6-well $\left(1 \times 10^{6} \mathrm{cells} / \mathrm{mL}\right), 24$-well $\left(5 \times 10^{4}\right.$ cells $\left./ \mathrm{mL}\right)$, or 96-well $\left(1 \times 10^{4}\right.$ cells $\left./ \mathrm{mL}\right)$ Ultra Low Attachment plates (Corning, Corning, NY, USA) and subsequent organization into tumor spheroids for at least $48 \mathrm{~h}$ (Sato et al. 2016).

\section{Side-population assays}

Single CA5171 cell suspensions were stained with $5 \mu \mathrm{g} / \mathrm{mL}$ Hoechst 33342 dye (Sigma-Aldrich) for $45 \mathrm{~min}$ at $37^{\circ} \mathrm{C}$. Propidium iodide was used to exclude nonviable cells. A total of $100 \mu \mathrm{M}$ verapamil (Sigma-Aldrich) was then added to inhibit drug efflux pump proteins. The cells were analyzed using a MoFlo XDP cell sorter (Beckman Coulter; Chiba et al. 2006).

\section{Aldefluor assay}

ALDH is a marker of stemness phenotypes. Aldefluor reagent (StemCell Technologies, Vancouver, Canada), a fluorescent non-toxic substrate for ALDH, was used to detect ALDH activity in spheroids. Spheroids were suspended in Aldefluor assay buffer containing the ALDH substrate and incubated for $45 \mathrm{~min}$ at $37^{\circ} \mathrm{C}$. As a negative control, suspended spheroids in the same conditions were treated with diethylaminobenzaldehyde, a specific ALDH enzyme inhibitor. Propidium iodide was added for a $15 \mathrm{~min}$ before analysis on a BD FACSCalibur flow cytometer (Nakahata et al. 2015).

\section{Apoptotic assays}

To evaluate the apoptosis of various tumor cell lines, their transfectants and their spheroids treated with cytotoxic drugs, cells were first incubated with $1 \mu \mathrm{M}$ of paclitaxel or $300 \mu \mathrm{M}$ of cisplatin for $48 \mathrm{~h}$. Then cells were stained with FITC-conjugated annexin V and 7-AAD (BD Biosciences, San Jose, CA, USA), following the manufacturer's instructions, and finally analyzed by flow cytometry as described earlier. Cells treated with DMSO were used as the negative control.
(C) 2019 Society for Endocrinology Published by Bioscientifica Ltd. Printed in Great Britain 


\section{Xenograft animal model}

Six to 8-week-old female SCID mice were purchased from the National Laboratory Animal Center (Taipei, Taiwan) and bred in the animal facility of the School of Medicine of National Taiwan University. All animal procedures were carried out according to approved protocols and in accordance with recommendations for the proper use and care of laboratory animals by the animal ethic committee of College of Medicine, National Taiwan University.

In a limit dilution assay, SCID mice ( 3 per group) were challenged with $1 \times 10^{6}, 1 \times 10^{5}$ or $1 \times 10^{4}$ CA5171 parental and CA5171 cancer stem-like cells (cultured for 21 days) subcutaneously. Before being injected, cells were resuspended in a 100 $\mu \mathrm{L}$ 1:1 RPMI-1640 and PanaceaGel (Menicon Co., Ltd., Kasugai, JP) mixture. Tumor growth was monitored weekly by inspection and palpation, and the size of each tumor was measured and recorded.

To compare tumor growth of cancer stem-like cells with or without expression of CHI3L1, equal numbers of various cells $\left(1 \times 10^{6}, 1 \times 10^{5}\right.$, or $\left.1 \times 10^{4}\right)$ were cultured to form spheroids under stem cell conditions for $48 \mathrm{~h}$. Total spheroids of each group were then harvested and suspended in the single cell suspension. All cancer stem-like cells were resuspended in $100 \mu \mathrm{L}$ 1:1 RPMI-1640 mixed with PanaceaGel (Menicon Co., Ltd.), injected subcutaneously into the right leg of SCID mice. Tumor growth was monitored and recorded twice per week.

\section{Reverse-transcription-PCR (RT-PCR)}

Total mRNA of various tissue specimens, ovarian cancer cell lines and their transfectants was first isolated by TRIzol RNA isolation kit according to the manufacturer's instructions. The Moloney murine leukemia virus reverse transcriptase kit was then used to generate all the cDNA template. To generate CHI3L1, the sense primer TGTGAAGGCGTCTCAAACAG and anti-sense primer AATTCGGCCTTCATTTCCTT were used in PCR for 30 cycles, as described previously (Chiang et al. 2015a). GAPDH was used as the housekeeping gene, generated with the sense primer ACCCAGAAGACTGTGGATGG and anti-sense primer TGCTGTA GCCAAATTCGTTG and used for 30 cycles at $58^{\circ} \mathrm{C}$, as described (Chiang et al. $2015 a$ ). Analysis of PCR products was performed by electrophoresis ( $1 \%$ agarose gel with ethidium bromide) (Sigma) staining in TBE (a buffer mixture of Tris base, boric acid and EDTA) solution.

\section{Quantitative real-time PCR (QRT-PCR)}

The cDNA templates were synthesized as previous described (Chiang et al. 2015a). The primer Hs00609691_m1 (TaqMan Assays, Life Technologies Corporation) was used to detect the expression of CHI3L1 by a LightCycler Real-Time detection system (Roche Diagnostics) with 50 cycles of $10 \mathrm{~s}$ at $95^{\circ} \mathrm{C}, 10 \mathrm{~s}$ at $60^{\circ} \mathrm{C}$ and $10 \mathrm{~s}$ at $72^{\circ} \mathrm{C}$. Internal control was performed using the LightCycler h-GAPDH housekeeping gene set (Roche Applied Science) with 50 cycles of $10 \mathrm{~s}$ at $95^{\circ} \mathrm{C}, 15 \mathrm{~s}$ at $55^{\circ} \mathrm{C}$ and $15 \mathrm{~s}$ at $72^{\circ} \mathrm{C}$.

The expression of CHI3L1 was calculated by using the comparative $2-\Delta \Delta \mathrm{Ct}$ method as described previously (Livak \& Schmittgen 2001). The Ct value was counted by the number of cycles needed for amplification-generated fluorescence to reach a specific threshold of detection. The expression level of CHI3L1 in each sample was used to follow equation: Relative expression level of $\mathrm{CHI} 3 \mathrm{~L} 1=2^{-\Delta \Delta \mathrm{Ct}}, \Delta \mathrm{Ct}=\mathrm{Ct}_{\text {target (CHI3L1) }}-\mathrm{Ct}_{\text {housekeeping (GAPDH) }}$.

\section{Enzyme-linked immunosorbent assay}

ELISA was performed to evaluate CHII3L1 concentrations in various cancer cell media. Cells $\left(2.5 \times 10^{5}\right.$ cells $\left./ \mathrm{mL}\right)$ were seeded in a six-well culture plate and incubated for $48 \mathrm{~h}$. Culture media were then collected and detected using ELISA kits (R\&D Systems).

\section{Immunoblotting}

Immunoblotting assays were performed to detect various expression levels of CHI3L1, stemness-related proteins and signaling pathway proteins in OVCAR3, CA5171 and their transfectant cells. To measure alterations in stemness gene expression during spheroid formation, cancer cells $\left(1 \times 10^{6}\right.$ cells $\left./ \mathrm{mL}\right)$ were suspended in six-well Ultra Low Attachment plates (Corning) and incubated for $48 \mathrm{~h}$ for spheroid formation. Spheroids were harvested and lysed in protein extraction buffer containing proteinase $\mathrm{K}$ inhibitor. The BCA Protein Assay Kit (Thermo Fisher Scientific) was used to quantify protein extracts. Equal amounts of protein were resolved on 10\% SDS-PAGE gels, transferred to a PVDF/nylon membrane (EMD Millipore) and probed with Abs specific to $\alpha$-tubulin (Abcam), $\beta$-catenin (Abcam), CHI3L1 (R\&D Systems), Nanog (OriGene Technologies, Rockville, MD, USA) and SOX2 and Oct-4 (Cell Signaling). The membrane was then incubated with HRP-conjugated rabbit anti-mouse (Hycult Biotechnology, Uden, Netherlands) and goat anti-mouse (R\&D Systems) secondary Abs. The ECL western blotting system (Perkin Elmer) was used to visualize specific bands, 
and ImageQuant 5.0 software (Molecular Dynamics Inc., Sunnyvale, CA, USA) was used to measure protein levels through densitometric analysis.

For signaling pathways involved in the spheroid formation, OVCAR3 tumor cells were seeded in six-well Ultra Low Attachment plates under stem cell conditions as described earlier and treated with various concentrations of recombinant human CHI3L1 protein (R\&D Systems) for $30 \mathrm{~min}$. To evaluate the phosphorylation of various proteins, Phospho-p44/42 MAPK, Phospho-Jnk, p44/42 MAPK, Akt, JNK (all from Cell Signaling) and phosphoAkt (Santa Cruz Biotechnology) were used as primary Abs, and HRP-conjugated rabbit anti-mouse (Hycult Biotechnology) was used as the secondary Ab.

In the signal transduction pathways blockade assays, OVCAR3 cells cultured in Ultra Low Attachment plates under stem cell conditions were first treated with the respective inhibitor (PD98059, 50 $\mu \mathrm{M}$; LY294002, $50 \mu \mathrm{M}$; Sigma-Aldrich) for $2 \mathrm{~h}$, followed by exposure to recombinant human CHI3L1 protein for $30 \mathrm{~min}$. Cells were then extracted and immunoblotted to detect expression of the respective molecules in various signaling pathways, as previously described.

\section{Generation of overexpressing and knockdown CHI3L1 in ovarian cancer cell lines}

The lentivirus-packaging plasmids, PLKO_AS3w.puro, $\Delta 8.91$ and pMD.G were purchased from the National RNAi Core Facility (Academia Sinica, Taiwan). Fulllength CHI3L1 was first generated by PCR using human placenta cDNA as the template and the following set of primers: sense, Hu-CHI3L1_S_NheI GGCTAGCACCATGGGTGTGAAGGCGTCTCAAAC; and anti-sense, (PstI) Hu-CHI3L1_AS_ PstI TAACTGCAGCTCAGCCTGGGACTCAGCA (PCR conditions). The results were cloned into the NheI/PstI sites of PLKO_AS3w.puro vector, designated as PLKO_AS3w CHI3L1.puro. To generate CHI3L1 lentivirus, 293T cells were co-transfected with three plasmids, pLKO_AS3wCHI3L1.puro, $\Delta 8.91$ and pMD.G, in a total transfection volume of $6 \mathrm{~mL}$ of Opti-MEM medium containing Lipofectamine 2000 reagent in $10 \mathrm{~cm}$ dishes and incubated at $37^{\circ} \mathrm{C}$ under $5 \% \mathrm{CO}_{2}$ for $48 \mathrm{~h}$ (Chiang et al. 2015a).

To generate the CHI3L1-overexpressing OVCAR3 transfectants, OVCAR3 cells were infected by CHI3L1 lentivirus in culture medium with polybrene $(10 \mu \mathrm{g} / \mathrm{mL})$ and incubated at $37^{\circ} \mathrm{C}$ under $5 \% \mathrm{CO}_{2}$ for $48 \mathrm{~h}$ (Chiang et al. 2015a). The PLKO_AS3w.puro was used to generate the blank lentivirus as the negative control. To select stable CHI3L1-overexpressing OVCAR3 transfectants, puromycin $(3 \mu \mathrm{g} / \mathrm{mL})$ was added to the culture medium and incubated at $37^{\circ} \mathrm{C}$ under $5 \% \mathrm{CO}_{2}$ for more than $48 \mathrm{~h}$. The puromycin-resistant $\mathrm{CHI} 3 \mathrm{~L} 1$-overexpressing OVCAR3 transfectants OVCAR3/CHI3L1-C4 and OVCAR3/CHI3L1-C9 were individually picked, expanded and used in the subsequent experiments.

TogenerateCHI3L1-knockdown CA5171 transfectants, CHI3L1 shRNA plasmid was purchased from the National RNAi Core Facility (Academia Sinica, Taiwan). The CHI3L1 shRNA lentivirus was generated by co-transfection with shRNA plasmid and $\triangle 8.91$ and pMD.G in Opti-MEM medium containing Lipofectamine2000 and incubated at $37^{\circ} \mathrm{C}$ under $5 \% \mathrm{CO}_{2}$ for $48 \mathrm{~h}$ (Chiang et al. 2015a). The PLKO_AS3w.puro was used to generate the blank lentivirus as the negative control. CA5171 cancer cells were infected by CHI3L1 shRNA lentivirus in culture medium with polybrene $(10 \mu \mathrm{g} / \mathrm{mL})$ and incubated at $37^{\circ} \mathrm{C}$ under $5 \%$ $\mathrm{CO}_{2}$ for $48 \mathrm{~h}$. For selecting stable CHI3L1-knockdown CA5171 transfectants, puromycin $(3 \mu \mathrm{g} / \mathrm{mL})$ was added to the culture medium and incubated at $37^{\circ} \mathrm{C}$ under $5 \% \mathrm{CO}_{2}$ for more than $48 \mathrm{~h}$. The puromycin-resistant CHI3L1knockdown CA5171 transfectants, CA5171/shCHI3L1-S1 and CA5171/shCHI3L1-S2, were individually picked, expanded and used in the subsequent experiments.

\section{Transfection of siRNA (small interfering RNA)}

siRNA for SOX2 and CTNNB1 ( $\beta$-catenin) was designed by and purchased from OriGene Technologies Inc. (Rockville, MD, USA). The duplex sequence of SOX2 was SR304528CrGrGrUrUrGrArCrArCrCrGrUrUrGrGrUrArArUrUrUrA rUAA, and the duplex sequence of CTNNB1 ( $\beta$-catenin) was SR301063A-rGGAUCACAAGAUGGAAUUUAUCAAA. The negative control was the siRNA duplex carrying a 27-mer scrambled sequence from OriGene's siRNA genespecific products. OVCAR3 and CHI3L1-overexpressing OVCAR3 transfectants were seeded in 6-well culture plates (Corning) overnight and then transfected with siRNA SOX2 or siRNA CTNNB1 ( $\beta$-catenin) in a final concentration of $100 \mathrm{nM}$ using Lipofectamine 2000 transfection reagent (Invitrogen) and in a total of $2 \mathrm{~mL}$ of serum-free RPMI 1640 medium. After incubation at $37^{\circ} \mathrm{C}$, $5 \% \mathrm{CO}_{2}$ for $12 \mathrm{~h}, 2 \mathrm{~mL}$ of RPMI 1640 medium containing $20 \%$ FBS was added. All cells were harvested and prepared for the subsequent experiments.

\section{Statistical analysis}

SPSS version 15.0 (SPSS Inc) was used for data analysis. Statistical analyses were carried out using Kruskal-Wallis 
or one-way ANOVA test. Survival curves were generated using the Kaplan-Meier method, and differences in survival curves were calculated using the log-rank test. A $P$ value $<0.05$ was considered to indicate statistical significance.

\section{Ethics approval and consent}

Animal handling and procedures were approved by the animal ethic committee of College of Medicine, National Taiwan University (20160416). The Institutional Review Board of the National Taiwan University Hospital approved the study entitled 'Screening and identification of novel diagnostic and prognostic biomarkers on ovarian cancers' (200706002R) to collect the human tissues after acquiring the informed consents.

\section{Results}

\section{High mRNA expression level of CHI3L1 correlated with chemoresistance and shorter DFS and OS}

The clinicopathological characteristics of these cases are shown in Table 1 . The mean follow-up duration was 39.0 months. The serous type was $75 \%(85 / 113)$ and tumor grade 3 was $92 \%(104 / 113)$ in all cases. The percentage of optimal debulking in all case was 50\%. The median mRNA expression level of the CHI3L1 was 7.6 (range 0.0-668.0).

Chemoresistant patients had the higher median of CHI3L1 mRNA level $(18.5 \pm 16.3$ vs $4.3 \pm 2.5$, KruskalWallis test, $P=0.001$, Fig. 1A) than chemosensitive patients. Besides, high CHI3L1 group ( $\geq 7.6)$ had both of shorter DFS (Fig. 1B) and OS (Fig. 1C) than low CHI3L1 group (log-rank test, $P<0.001$ ).
Based on the clinical and outcome results, we hypothesized that the biologic role of CHI3L1 in ovarian cancer is to promote ovarian cancer stem cell formation.

\section{Characteristics of CA5171 cancer stem-like cells in parental and spheroid cells}

Representative figures of CA5175 parental cells and CA5171 spheroids are shown in Fig. 2A. Figure 2B shows representative results for side-population assays by flow cytometry. The percentages of CA5171 parental cells pumping out Hoechst33342 decreased from 2.8 to $0.7 \%$ under verapamil treatment. The estimated proportion of stem-like cells of the parental CA5171 line was around $2.1 \%$ by side-population assays.

CA5171 parental cells and spheroids expressing aldehyde dehydrogenase (ALDH) were further evaluated. As shown in Fig. 2C, 3.8\% of CA5171 parental cells expressed ALDH, whereas 55\% of CA5171 spheroid cells did so. These results indicated that percentages of cancer CA5171 stem-like cells increased by changing the culture media from regular medium to stem cell culture medium.

\section{Spheroid cells are more chemoresistant to cytotoxic drugs and tumorigenesis than are their parental cells}

The chemoresistant capabilities between CA5171 parental cells and spheroids were also evaluated. The $\mathrm{IC}_{50}$ for paclitaxel in CA5171 parental cells was around $0.11 \mu \mathrm{M}$ (Fig. 2D) whereas for CA5171 spheroid cells, it was $>1 \mu \mathrm{M}$. In addition, the $\mathrm{IC}_{50}$ values for cisplatin in CA5171 parental cells and their spheroid cells were 172.3 and $604.2 \mu \mathrm{M}$, respectively (Fig. 2D).
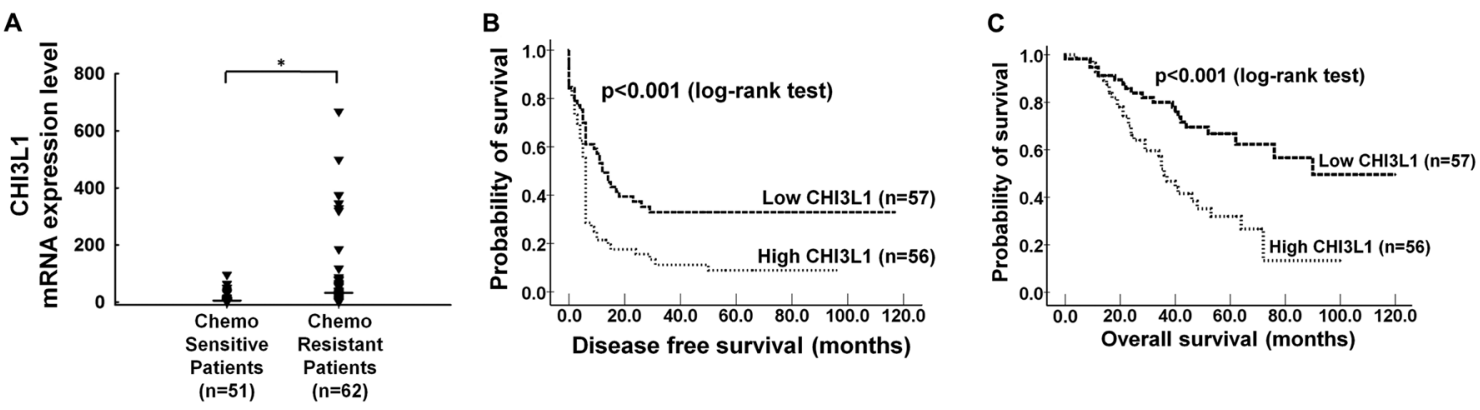

\section{Figure 1}

Correlation between the mRNA expression levels of CHI3L1 and chemoresistance and outcome of 113 ovarian cancer patients. (A) Correlation between the mRNA expression levels of CHI3L1 and chemoresistance. Chemoresistant patients had higher levels of CHI3L1 than chemosensitive patients (18.5 vs 4.3, $P=0.001$, Kruskal-Wallis test). (B) Correlation between mRNA expression levels of CHI3L1 and disease-free survival (DFS) of patients. The high CHI3L1 group had shorter DFS than low CHI3L1 group ( $P<0.001$, Log-rank test). (C) Correlation between mRNA expression levels of CHI3L1 and overall survival (OS) of patients. The high CHI3L1 group had shorter OS than low CHI3L1 group $(P<0.001$, Log-rank test) 


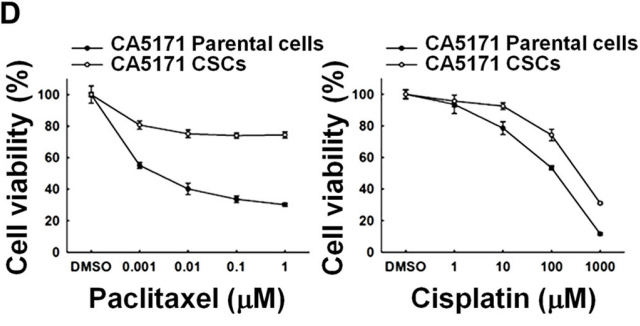

E

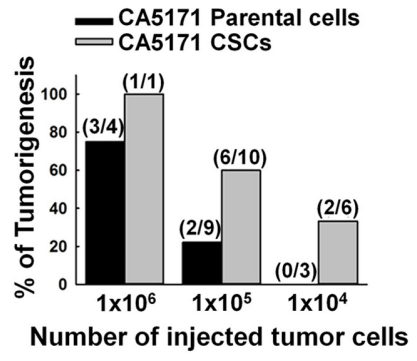

Figure 2

Characteristics of CA5171 cancer stem-like cells. (A) Representative images of CA5171 parental cells and spheroids in low- (40x) and high- (200x) power fields photographed using an inverted phase-contrast microscope. CA5171 parental cells could be cultured to CA5171 spheroids under stem cell conditions. (B) Side-population assays of CA5171 parental cells treated with DMSO or verapamil $(100 \mu \mathrm{M})$, stained with Hoechst 33342 dye, and then analyzed by flow cytometry. The percentages of CA5171 parental cells pumping out Hoechst33342 decreased from 2.8 to $0.7 \%$ under verapamil treatment. (C) ALDH ${ }^{+}$CA5171 parental cells and spheroids stained in Aldefluor assays. 3.8\% of CA5171 parental cells expressed ALDH compared to $55 \%$ of CA5171 stem-like cells. (D) Cytotoxicities of CA5171 parental cells and spheroids treated with cytotoxic drugs by MTT assays. CA5171 spheroids had significantly higher $\mathrm{IC}_{50}$ concentrations compared to parental cells under either paclitaxel or cisplatin treatment. (E) In vivo tumor growth experiments with CA5171 parental cells and its spheroids. Cell numbers for in vivo tumorigenesis were fewer in CA5171 spheroid cells than in CA5171 parental cells. A full color version of this figure is available at https:// doi.org/10.1530/ERC-18-0300.
We also assessed in vivo tumorigenic capabilities. The subcutaneous tumors in CA5171 parental and spheroid cell-bearing mice are shown in Fig. 1E. Injection with $1 \times 10^{4}$ CA5171 parental cells yielded no tumorigenesis in the mice; however, injection with $1 \times 10^{4}$ CA5171 spheroid cells resulted in tumorigenesis in two out of six animals (Fig. 2E). These results indicate that CA5171 spheroid cells are more chemoresistant and prone to in vivo tumorigenesis than are CA5171 parental cells.

\section{Exogenous CHI3L1 promotes the properties of ovarian cancer stem-like cells}

The roles and biologic functions of CHI3L1 in ovarian cancer stem-like cells were further investigated. Representative images of CHI3L1 mRNA expression levels in CA5171 parental cells and its spheroids are shown in Fig. 3A. The CA5171 spheroids expressed 3-folds of CHI3L1 mRNA higher than CA5171 parental cells (Fig. 3B). Figure 3C shows representative results for spheroids from OVCAR3 parental cells treated with recombinant human CHI3L1 protein. The average spheroid sizes (around 150-250 $\mu \mathrm{m}$ ) of OVCAR3 parental cells treated with $1000 \mathrm{ng} / \mathrm{mL}$ of CHI3L1 were larger than with $100 \mathrm{ng} / \mathrm{mL}$ of CHI3L1 or PBS only (100-150 $\mu \mathrm{m})$ (Fig. 3C).

In addition, the percentages of $\mathrm{ALDH}^{+}$OVCAR3 cells treated with CHI3L1 increased in a dose-dependent manner $(1.2 \%$ in PBS, $3.6 \%$ in $100 \mathrm{ng} / \mathrm{mL}$ and $4.3 \%$ in $1000 \mathrm{ng} / \mathrm{mL}$; Fig. 3D). Protein levels of stemness-related genes including SOX2, NANOG, OCT4 and CTNNB1 ( $\beta$-catenin) were analyzed by immunoblotting. As shown in Fig. 3E, the protein levels of SOX2 and CTNNB1 ( $\beta$-catenin) of OVCAR3 parental cells increased in a dosedependent manner when treated with recombinant CHI3L1. In contrast, protein levels of NANOG or OCT4 did not change under treatment with recombinant CHI3L1 (Fig. 3E).

Apoptotic assays of OVCAR3 cells treated with CHI3L1 were further evaluated. With culture of cells under stem cell conditions with or without CHI3L1, OVCAR3 cells treated with $1000 \mathrm{ng} / \mathrm{mL}$ of CHI3L1 had the lowest percentages of apoptotic cells $(17.6 \pm 0.1 \%)$ compared with those treated with $100 \mathrm{ng} / \mathrm{mL}$ of CHI3L1 $(12.6 \pm 0.2 \%)$ or PBS alone $(8.3 \pm 0.1 \%)(P<0.001$, one-way ANOVA) (Fig. 3F).

\section{CHI3L1-overexpressing cancer cells generate the properties of cancer stem-like cells}

The mRNA expression levels of CHI3L1 in OVCAR3/CHI3L1 transfectants and CA5171/shCHI3L1 transfectants are shown in Fig. 4A. The concentrations of CHI3L1 protein $(\mathrm{ng} / \mathrm{mL})$ in the culture media of OVCAR3 /CHI3L1 transfectants (C4 (52.8 \pm 3.7$)$ and C9 (59.6 \pm 2.4$))$ 


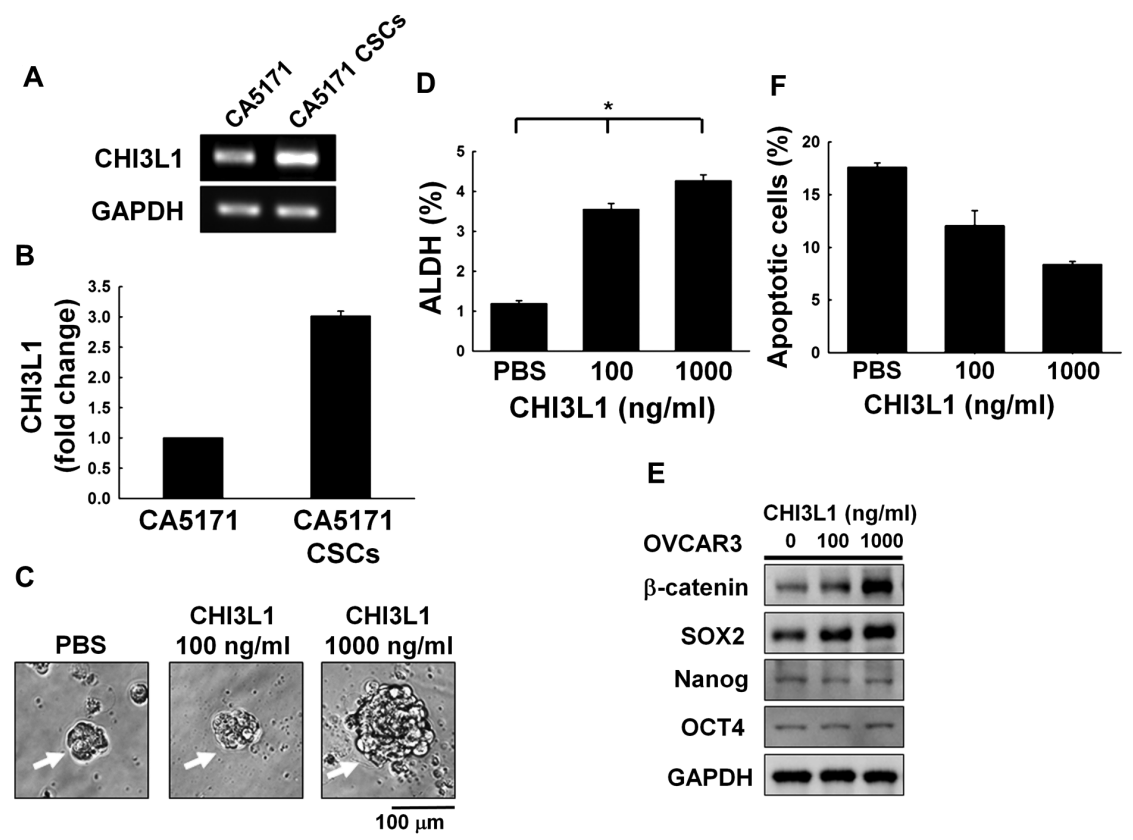

\section{Figure 3}

CHI3L1 expression promotes cancer stem-like cell properties in OVCAR3 tumor cells. (A) CHI3L1 mRNA expression levels in CA5171 parental cells and spheroids by RT-PCR. CHI3L1 RNA expression was higher in CA5171 spheroids than in CA5171 parental cells. (B) Bar graphs of CHI3L1 mRNA expression levels in CA5171 parental cells and spheroids by RT-PCR. The CA5171 spheroids expressed CHI3L1 3 folds higher than CA5171 parental cells. (C) The representative images of spheroids from OVCAR3 parental cells treated with recombinant human CHI3L1 protein. OVCAR3 parental cells treated with CHI3L1 $(1000 \mathrm{ng} / \mathrm{mL})$ generated larger spheroid sizes than treated with PBS or $100 \mathrm{ng} / \mathrm{mL}$ of CHI3L1. (D) Percentages of ALDH ${ }^{+}$OVCAR3 tumor cells treated with different concentrations of CHI3L1, as detected by Aldefluor assays and flow cytometric analysis. OVCAR3 parental cells under stem cell conditions treated with CHI3L1 increased the ratio of ALDH+ OVCAR3 cancer cells. (E) Immunoblotting analysis of expression of stemness-related molecules in OVCAR3 tumor cells treated with different concentrations of CHI3L1. Cultured OVCAR3 parental cells under stem cell conditions with CHI3L1 regulated expression of $\beta$-catenin and SOX2 with no change in Nanog or OCT4. (F) Percentages of apoptotic cells of OVCAR3 tumor cells treated with different concentrations of CHI3L1, as detected in apoptotic assays and by flow cytometric analysis. CHI3L1 enhanced the viability of OVCAR3 parental cells under stem cell conditions.

were higher than those of OVCA3/mock transfectants (5.5 \pm 0.3$)(P<0.001$, one-way ANOVA) (Fig. 4B). However, the concentrations of CHI3L1 protein $(\mathrm{ng} / \mathrm{mL})$ in the culture media of CA5171/shCHI3L1 transfectants (S1 (5.6 \pm 0.6$)$ and S2 $(2.8 \pm 0.5)$ were lower than those of CA5171/mock transfectants $(25.0 \pm 1.6)(P<0.001$, one-way ANOVA) (Fig. 4B).

The representative images of spheroid formation in different OVCAR3 transfectants and CA5171 transfectants are shown in Fig. 4C. The OVCAR3/CHI3L1-C4 $(103.3 \pm 10.6)$ and C9 $(103.5 \pm 7.4)$ transfectants had more tumor spheroids (spheroid size $>100 \mu \mathrm{m}$ was counted) than OVCAR3/mock $(29.0 \pm 3.5)$ transfectants $(P<0.001$, oneway ANOVA; Fig. 4D). In contrast, the tumor spheroids

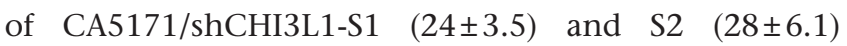
transfectants were fewer than CA5171/mock (71 \pm 9.3$)$ transfectants ( $P=0.001$, one-way ANOVA) (Fig. 4D).

Representative images of $\mathrm{ALDH}^{+}$cells in various ovarian parental lines and their CHI3L1 transfectants detected by flow cytometric analyses are shown in Fig. 4E. The OVCAR3/CHI3L1 transfectants (C4 (16.4 $\pm 1.2 \%)$ and C9 $(18.3 \pm 1.0 \%))$ had higher percentages of $\mathrm{ALDH}^{+}$cells than OVCAR3/mock transfectants $(1.2 \pm 0.1 \%)(P=0.017$, one-way ANOVA; Fig. 4F). The CA5171/shCHI3L1 transfectants (S1 $(25.6 \pm 2.5 \%)$ and S2 cells $(28.1 \pm 2.3 \%)$ ), however, had lower percentages of $\mathrm{ALDH}^{+}$cells than the CA5171/mock transfectants $(51.4 \pm 0.7 \%)(P=0.002$, one-way ANOVA; Fig. 3F).

Immunoblotting analysis of various CHI3L1 transfectants for stemness-related genes was performed. The protein expression levels of SOX2 and $\beta$-catenin (CTNNB1) were higher in both OVCAR3/CHI3L1 transfectants (C4 and C9) than in OVCAR3/mock transfectants. In contrast, protein levels of SOX 2 and $\beta$-catenin were lower in CA5171/shCHI3L1 transfectants (S1 and S2) than in CA5171/mock transfectants (Fig. 4G).

\section{CHI3L1 stimulates both of Erk and Akt phosphorylation during tumor spheroid formation}

We then further evaluated the signaling pathways involved in CHI3L1-related tumor spheroid formation. The representative images of immunoblotting results are 
D

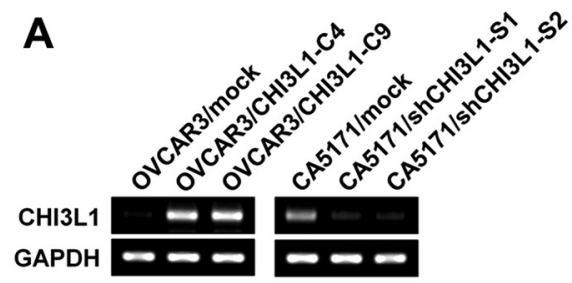

B

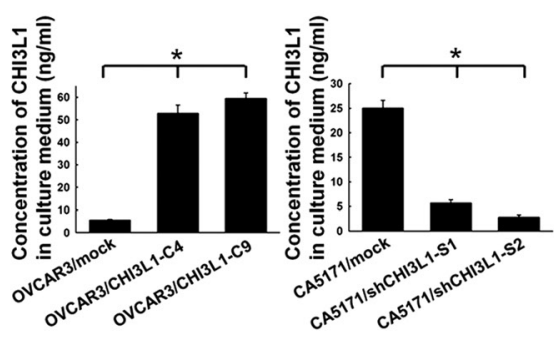

C

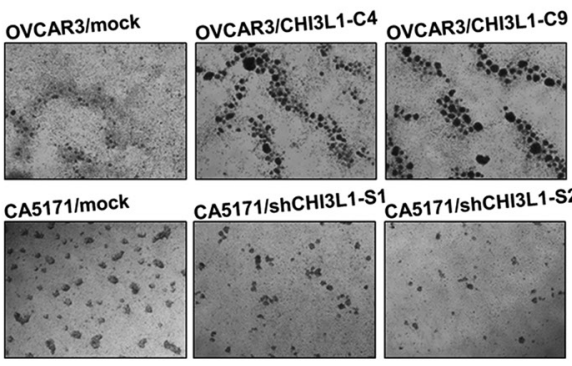

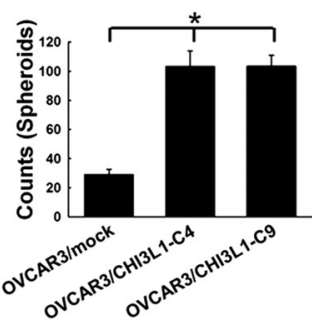

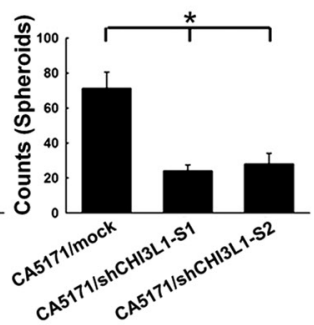

E

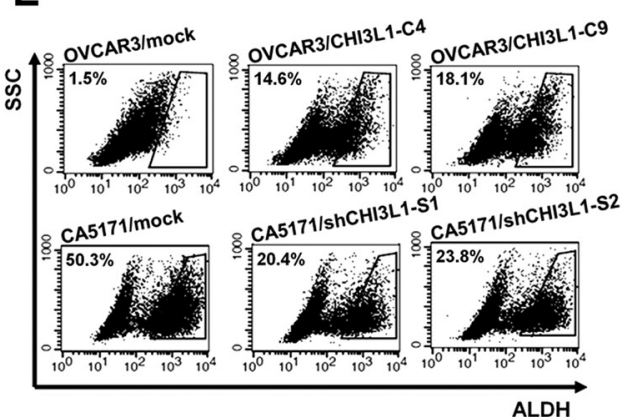

(F)

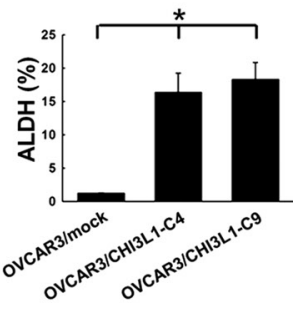

G

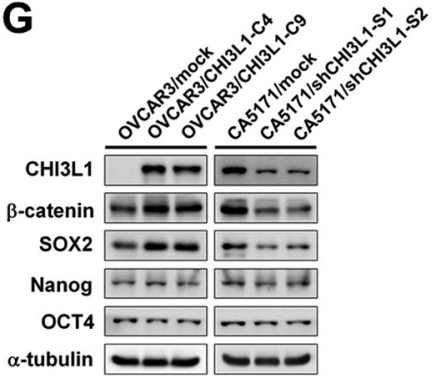

H
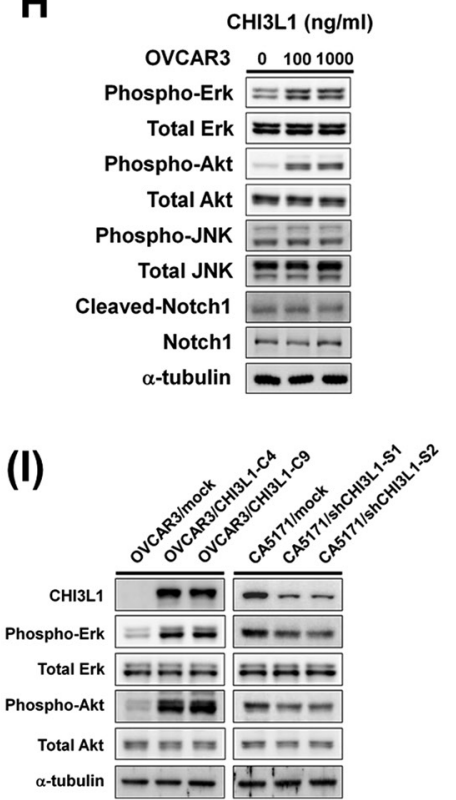

Figure 4

Expression of CHI3L1 in ovarian cancer cells altered the quantity of spheroids and stemness properties and stimulated both phospho-Akt and phosphoErk pathways under stem cell conditions. (A) CHI3L1 RNA expression levels of OVCAR3 parental cells and their CHI3L1 transfectants and of CA5171 parental cells and their shCHI3L1 transfectants, as detected by RT-PCR. (B) CHI3L1 protein concentrations in culture media of OVCAR3 parental cells and their CHI3L1 transfectants and of CA5171 parental cells and their shCHI3L1 transfectants as detected by ELISA. CHI3L1 mRNA and protein expression levels were both high in OVCAR3 CHI3L1 transfectants, whereas they were low in CA5171 shCHI3L1 transfectants, as detected by RT-PCR and ELISA. (C) Representative images of spheroid formation of OVCAR3 parental cells and their CHI3L1 transfectants, and CA5171 parental cells and their shCHI3L1 transfectants. (D) Bar graphs of the numbers of spheroids in OVCAR3 parental cells and their CHI3L1 transfectants and of CA5171 parental cells and their shCHI3L1 transfectants. Numbers and sizes of spheroids of OVCAR3 CHI3L1 transfectants under stem cell conditions were both increased compared with controls (mock), but those of CA5171 shCHI3L1 transfectants were both decreased compared with controls. (E) Representative images of the percentages of $\mathrm{ALDH}^{+}$OVCAR3 parental cells and their CHI3L1 transfectants and of CA5171 parental cells and their shCHI3L1 transfectants, measured by flow cytometry. (F) Bar graphs of the percentages of ALDH+ OVCAR3 parental cells and their CHI3L1 transfectants and of CA5171 parental cells and their shCHI3L1 transfectants (right) by Aldefluor assays. The ratio of ALDH+ cells in spheroids of OVCAR3 CHI3L1 transfectants was increased compared with controls (mock), whereas that of $\mathrm{ALDH}^{+}$cells in spheroids of CA5171 shCHI3L1 transfectants was decreased. (G) Expression levels of various stemnessrelated genes in OVCAR3 parental cells and their CHI3L1 transfectants and of CA5171 parental cells and their shCHI3L1 transfectants, by immunoblotting analysis. Expression of $\beta$-catenin and SOX2 was increased in spheroids of OVCAR3 CHI3L1 transfectants under stem cell conditions but decreased in spheroids of CA5171 shCHI3L1 transfectants, and there was no change in Nanog or OCT4. (H) Phosphorylation of various signaling molecules of OVCAR3 tumor cells treated with different concentrations of CHI3L1 detected by immunoblotting. CHI3L1 stimulated phosphorylation of Akt and Erk in spheroids of OVCAR3 parental cells under stem cell conditions. (I) Phosphorylation of various signaling molecules of OVCAR3 parental cells and their CHI3L1 transfectants and of CA5171 parental cells and their shCHI3L1 transfectants, as detected by immunoblotting. Under stem cell conditions, phosphorylation of Akt and Erk increased in spheroids of OVCAR3 CHI3L1 transfectants and decreased in spheroids of CA5171 shCHI3L1 transfectants.

shown in Fig. 4H. The phosphorylation of Erk1/2 and Akt increased in cells treated with recombinant CHI3L1 under stem cell conditions (Fig. 4H). However, the phosphorylation of JNK or cleavage of Notch1 did not change even under CHI3L1 treatment.
The CHI3L1-overexpressing OVCAR3 transfectants (OVCAR3/CHI3L1-C4 and -C9) also revealed increasing phosphorylation of Erk1/2 and Akt compared with the OVCAR3/mock transfectants (Fig. 4I). CHI3L1-downregulated CA5171 transfectants 
(CA5171/shCHI3L1-S1 and -S2), on the other hand, had less Erk1/2 or Akt phosphorylation than the CA5171/mock transfectants (Fig. 4I).

\section{CHI3L1 could enhance tumor spheroid formation and characteristics of cancer stem-like cells through the Erk and Akt signaling pathways}

To confirm the essential signaling pathway of CHI3L1 in tumor spheroid formation, specific pathway inhibitors such as LY294002 for Akt or PD98059 for Erk were further tested. As shown in Fig. 5A, Erk phosphorylation decreased when cells were cultured with recombinant human CHI3L1 and PD98059 (lane 3) or PD98059 alone (lane 5). In addition, Akt phosphorylation also decreased with cells cultured in recombinant human CHI3L1 and LY294002 (lane 4) or LY294002 alone (lane 6).

We then evaluated if a specific inhibitor of the Akt or Erk signaling pathway could inhibit the CHI3L1regulated spheroid formation and the generation of stem-like cells. The representative figures of spheroid formation of various OVCAR3 and CA5171 cells and their respective CHI3L1 transfectants are shown in Fig. 5B and C. The spheroid sizes and numbers of OVCAR3 parental cells and OVCAR3/CHI3L1 transfectants decreased under treatment with PD98059 or LY294002 (Fig. 5B). The sizes and numbers of CA5171 parental cells and CA5171/shCHI3L1 transfectants also decreased under these treatments (Fig. 5C).

We then further investigated the percentages of $\mathrm{ALDH}^{+}$cells. As shown in Fig. 5D, the percentages of $\mathrm{ALDH}^{+}$OVCAR3 cells cultured with recombinant human CHI3L1 significantly decreased when pretreated with PD98059 (4.2 $\pm 0.1 \%, P<0.001)$ or LY294002 $(2.9 \pm 0.1$, $P<0.001)$ compared with the control group $(6.4 \pm 0.1 \%)$ (one-way ANOVA). The percentages of $\mathrm{ALDH}^{+}$cells in OVCAR3 CHI3L1 transfectants were also lower when cells were pretreated with LY294002 (C4: $2.7 \pm 0.3 \%$; C9: $2.6 \pm 0.3 \%$ ) or PD98059 (C4: $8.0 \pm 0.8 \%$; C9: $8.6 \pm 1.0 \%$ ) compared with controls (C4: $15.7 \pm 0.5 \%, P<0.001$; and C9: $16.5 \pm 0.5 \%, P<0.001$ ) (one-way ANOVA) (Fig. $5 \mathrm{E}$ ). In addition, the OVCAR3/CHI3L1 transfectants treated with LY294002 had lower percentages of $\mathrm{ALDH}^{+}$cells than those treated with PD98059 $(P<0.001$, one-way ANOVA).

We further evaluated if the inhibition of CHI3L1regulated signaling pathways could enhance sensitivity to cytotoxic drugs. As shown in Fig. 5F, OVCAR3 parental cells cultured with recombinant human CHI3L1 $(138.4 \pm 3.7 \%)$ under stem cell conditions had higher percentages of viable cells than those treated with PBS
$(100.0 \pm 4.0 \%)$ when subsequently treated with paclitaxel. However, the percentages of OVCAR3 parental cells treated with PD98059 $(50.3 \pm 0.6 \%)$ or LY294002 $(8.7 \pm 0.1 \%)$ were lower than the OVCAR3 parental cells treated with PBS, when subsequently cultured with paclitaxel (oneway ANOVA, $P<0.001$ ) (Fig. 5G). The OVCAR3/CHI3L1 transfectants pretreated with LY294002 (C4: 12.5 $\pm 0.7 \%$; C9: $11.3 \pm 0.7 \%$ ) also had significantly lower percentages of viable cells than those pretreated with PD98059 (C4: $117.9 \pm 4.3 \%$; C9: $107.9 \pm 8.7 \%)(P<0.001$, one-way ANOVA) when cultured with paclitaxel.

\section{CHI3L1 regulates expression of $\beta$-catenin and SOX2 stemness-related molecules through the Akt and Erk signaling pathways}

We further evaluated which stemness-related molecules were regulated by CHI3L1 during tumor spheroid formation. As shown in Fig. 5H, the OVCAR3/CHI3L1 transfectants (C4 and C9) expressed higher levels of $\beta$-catenin and SOX2 molecules than OVCAR3 parental cells. The expression levels of Nanog or OCT4 did not differ between OVCAR3 parental cells and OVCAR3/CHI3L1 transfectants (Fig. 5H). PD98059 could only inhibit minor expression of SOX2, not $\beta$-catenin, in OVCAR3 parental cells and OVCAR3/CHI3L1 transfectants. LY294002, however, suppressed the expression of both $\beta$-catenin and SOX2 in OVCAR3 parental cells and OVCAR3/CHI3L1 transfectants. Our results revealed that CHI3L1 could regulate expression of $\beta$-catenin and SOX2 during spheroid formation, mainly through the Akt, not Erk, signaling pathway.

\section{$\beta$-catenin was upstream of SOX2 among the CHI3L1-regulated tumor spheroid formation and cancer stem-like characteristics}

We further assessed if CHI3L1 could regulate the formation and characteristics of cancer stem-like cells through $\beta$-catenin and SOX2. The $\beta$-catenin siRNA or SOX2 siRNA inhibited expression of their respective molecule in OVCAR3/CHI3L1 transfectants. Inhibition of $\beta$-catenin by $\beta$-catenin siRNA also suppressed the expression of SOX2 (Fig. 6A), but the inhibition of SOX2 by SOX2 siRNA did not influence the expression of $\beta$-catenin. As shown in Fig. $6 \mathrm{~B}$, the sizes and numbers of tumor spheroids of OVCAR3/CHI3L1 transfectants significantly decreased under treatment with $\beta$-catenin siRNA compared with those treated with scramble siRNA. 
A

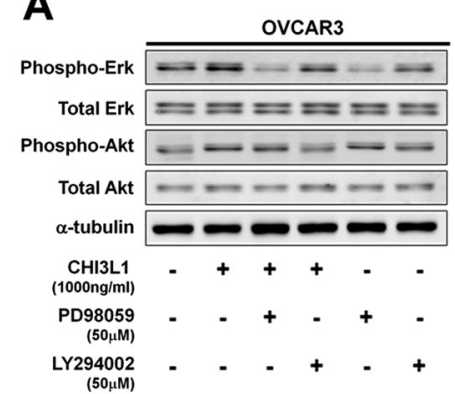

D

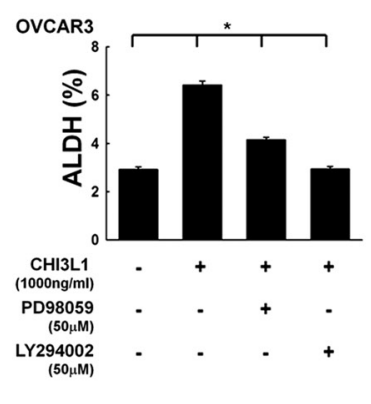

F

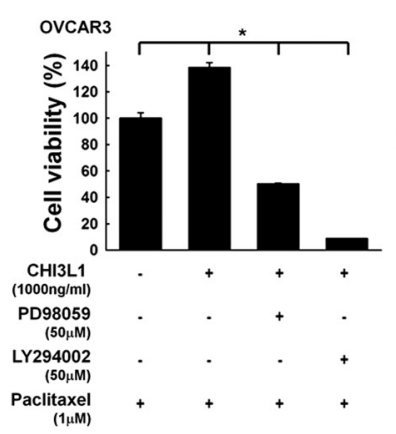

H

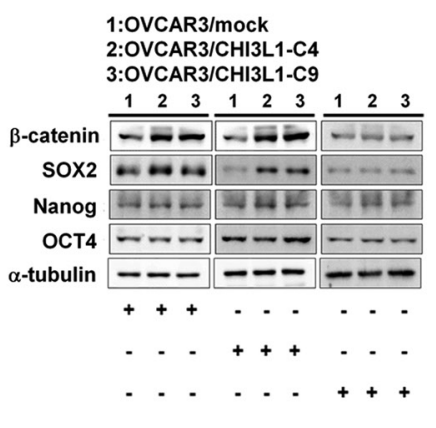

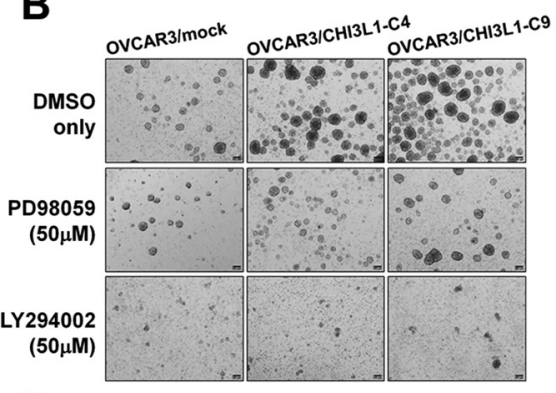

C CA5171/mock CA5171/ShCHI3L1-S1

E

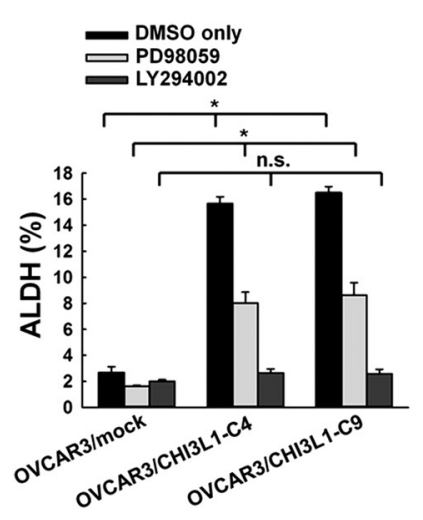

G

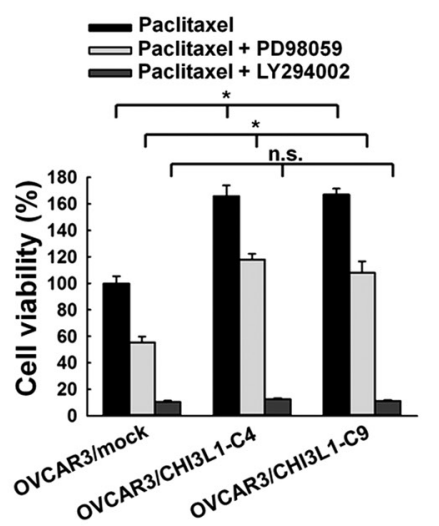

\section{Figure 5}

Inhibition of phospho-Akt and phosphor-Erk pathways impaired spheroid formation. (A) LY249002 and PD98059 inhibited phospho-Akt and phosphor-Erk pathways stimulated by CHI3L1 under stem cell conditions. Under these conditions, CHI3L1 stimulated phosphorylation of Akt and Erk in spheroids of OVCAR3 parental cells, and LY294002 and PD98059 inhibited phosphorylation of Akt and Erk, respectively, stimulated by CHI3L1 in spheroids of OVCAR3 parental cells. (B) Representative image of OVCAR3 parental cells and their CHI3L1 transfectants cultured in stem cell media with LY294002 or PD98059 and photographed after $48 \mathrm{~h}$. (C) Representative image of CA5171 parental cells and their shCHI3L1 transfectants cultured in stem cell media with LY294002 or PD98059 and photographed after 48 h. LY294002 significantly decreased numbers and sizes of spheroids of OVCAR3 CHI3L1 transfectants under stem cell conditions and PD98059 decreased them partially; they both had the same respective effect on spheroids of the CA5171/mock group. (D) Percentages of $\mathrm{ALDH}^{+}$OVCAR3 tumor cells treated with CHI3L1 and LY294002 or PD98059, detected by Aldefluor assays and flow cytometric analysis. LY294002 decreased the ratio of $\mathrm{ALDH}^{+}$cells in spheroids of OVCAR3 parental cells cultured with CHI3L1 under stem cell conditions, and PD98059 decreased it partially. (E) Percentages of ALDH+ OVCAR3 parental cells and their CHI3L1 transfectants treated with CHI3L1 and LY294002 or PD98059, detected by Aldefluor assays and flow cytometric analysis. LY294002 significantly decreased the ratio of ALDH ${ }^{+}$cells in spheroids of OVCAR3 CHI3L1 transfectants under stem cell conditions, and PD98059 decreased it partially. (F) Percentages of apoptotic cells of OVCAR3 spheroids in the presence of paclitaxel and CHI3L1 treated with LY294002 or PD98059, detected by apoptotic and flow cytometric analyses. LY294002 considerably suppressed cell viability conferred by CHI3L1 in spheroids of OVCAR3 parental cells treated with paclitaxel under stem cell conditions, and PD98059 suppressed it partially. (G) Percentages of apoptotic OVCAR3 parental cells and their CHI3L1 transfectants treated with paclitaxel and LY294002 or PD98059, detected by apoptotic assays and flow cytometric analysis. LY294002 significantly suppressed cell viability in spheroids of OVCAR3 CHI3L1 transfectants treated with paclitaxel under stem cell conditions, and PD98059 suppressed it partially. (H) Expression levels of various stemness-related genes in OVCAR3 parental cells and their CHI3L1 transfectants after treatment with LY294002 or PD98059, detected by immunoblotting. LY294002 significantly suppressed expression of SOX2 and $\beta$-catenin in spheroids of OVCAR3 CHI3L1 transfectants under stem cell conditions, but PD98059 suppressed only SOX2 partially. Protein levels of Nanog and OCT-4 did not change.

The representative flow cytometric figures of ALDHexpressing OVCAR3/CHI3L1 transfectants treated with various siRNA are shown in Fig. 6C. As shown in Fig. 6D, $\beta$-catenin siRNA (C4: $8.1 \pm 1.6 \%$; C9: $6.1 \pm 1.6 \%$ ) and SOX2 siRNA (C4: $7.8 \pm 0.6 \%$; C9: $6.6 \pm 1.3 \%$ ) decreased the percentages of $\mathrm{ALDH}^{+}$OVCAR/CHI3L1 transfectants compared to scramble siRNA (C4: $18.9 \pm 2.7 \%, P<0.001$; C9: $16.8 \pm 1.5 \%, P<0.001$, one-way ANOVA). The percentages of $\mathrm{ALDH}^{+}$cells were no different between OVCAR/CHI3L1 transfectants treated with $\beta$-catenin siRNA and SOX2 
A
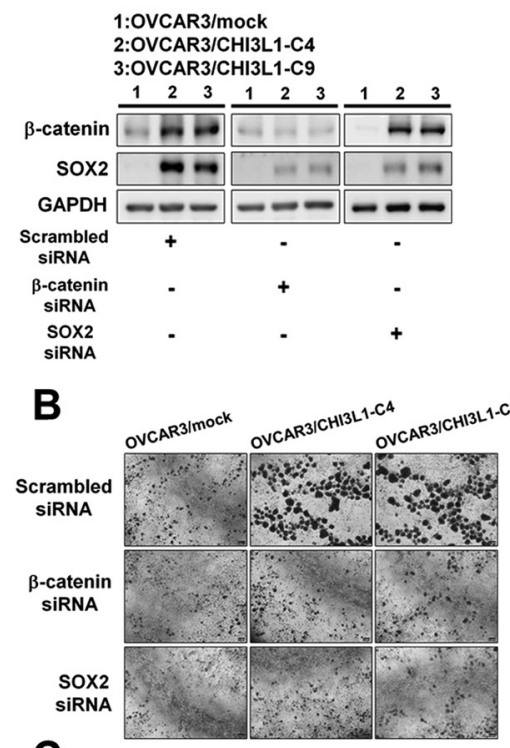

C

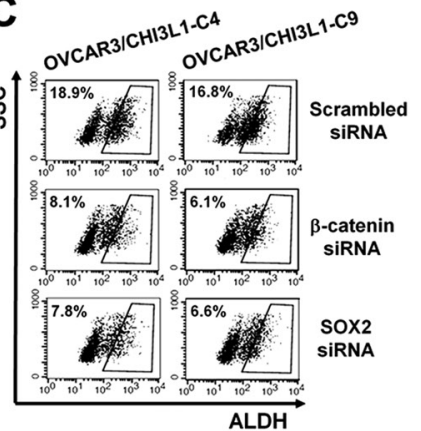

D

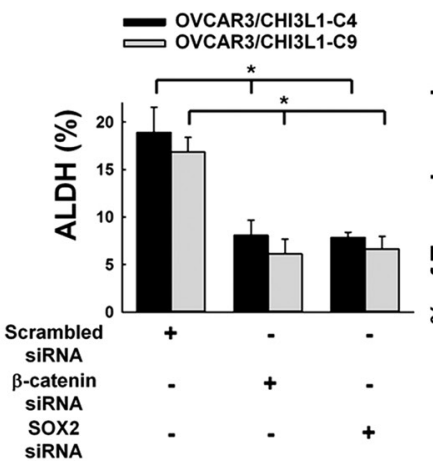

E

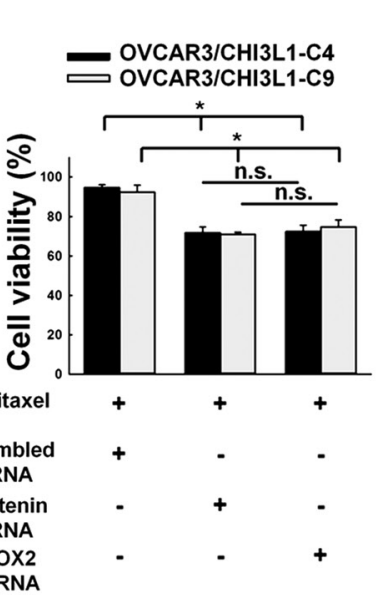

F

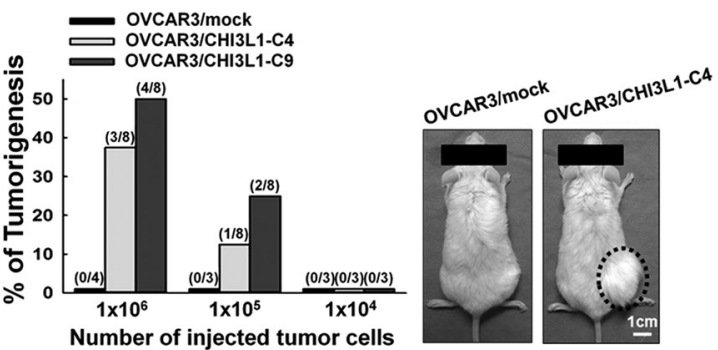

G

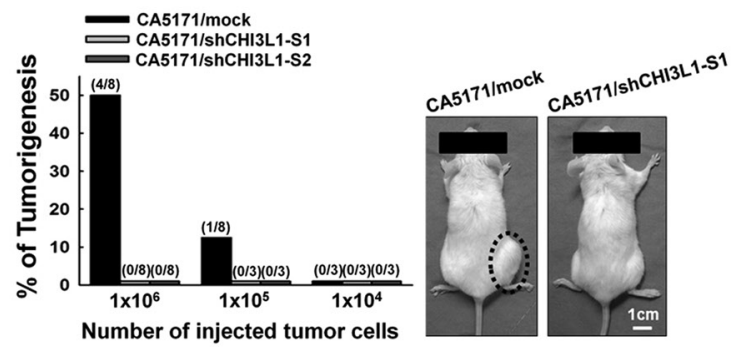

Figure 6

Knockdown of SOX2 or $\beta$-catenin impaired the formation of spheroids stimulated by CHI3L1. (A) The expression levels of SOX2 and $\beta$-catenin in OVCAR3 CHI3L1 transfectants after transfection with siRNA SOX2 or siRNA $\beta$-catenin, as detected by immunoblotting. Protein suppression of $\beta$-catenin by siRNA in spheroids of OVCAR3 CHI3L1 transfectants under stem cell conditions alone prevented SOX2 protein expression, but protein suppression of SOX2 by siRNA did not affect the protein expression of $\beta$-catenin. (B) OVCAR3 parental cells and their CHI3L1 transfectants after transfection with siRNA SOX2 or siRNA $\beta$-catenin for $48 \mathrm{~h}$ were harvested and cultured to spheroids under stem cell conditions and photographed (40x) after $48 \mathrm{~h}$. The formation of spheroids of OVCAR3 CHI3L1 transfectants decreased after the suppression of SOX2 or $\beta$-catenin protein expression by siRNA. (C) Representative images of the percentages of ALDH+ OVCAR3 parental cells and their CHI3L1 transfectants after transfection with siRNA SOX2 or siRNA $\beta$-catenin and culture to spheroids, measured by flow cytometry. (D) Bar graphs of the percentages of ALDH+ OVCAR3 parental cells and their CHI3L1 transfectants after transfection with siRNA SOX2 or siRNA $\beta$-catenin and culture to spheroids, measured by Aldefluor assays after $48 \mathrm{~h}$. The ratio of $\mathrm{ALDH}^{+}$cells in spheroids of OVCAR3 CHI3L1 transfectants under stem cell conditions was also decreased after the suppression of SOX2 or $\beta$-catenin protein expression by siRNA. (E) Percentages of apoptotic cells of OVCAR3 CHI3L1 transfectants transfected with siRNA SOX2 or siRNA $\beta$-catenin and cultured to spheroids with paclitaxel, as measured by apoptotic assays and flow cytometric analysis after 48 hours. siRNA SOX2 or siRNA $\beta$-catenin decreased the viability of OVCAR3/CHI3L1 transfectants under stem cell conditions and paclitaxel treatment. (F) In vivo limiting dilution assays for spheroids of OVCAR3 CHI3L1 transfectants. (G) In vivo limiting dilution assays for spheroids of CA5171 shCHI3L1 transfectants. The tumorigenicity of spheroids of OVCAR3 CHI3L1 transfectants increased faster than in OVCAR3 parental cells, as did the tumorigenicity of spheroids of CA5171 parental cells compared to CA5171 shCHI3L1 transfectants.

siRNA $(P>0.05$, one-way ANOVA). The $\beta$-catenin siRNA (C4: 71.8 $\pm 2.9 \%$; C9: 71.1 $\pm 0.9 \%$ ) and SOX2 siRNA (C4: $72.3 \pm 3.3 \%$, C9: $74.8 \pm 3.4 \%$ ) also decreased the percentages of viable OVCAR3/CHI3L1 transfected cells treated with paclitaxel compared to scramble siRNA (C4: $94.7 \pm 1.3 \%, P=0.002$; C9: $92.5 \pm 3.3 \%, P=0.002$, one-way ANOVA) (Fig. 6E).
CHI3L1 regulates the formation of cancer stem-like cells to enhance the tumorigenesis of ovarian cancer in vivo

We next investigated if OVCAR3/CHI3L1 transfectants could be more tumorigenic than OVCAR3 parental cells in vivo. As shown in Fig. $6 \mathrm{~F}$, when injected with $1 \times 10^{6}$ of the respective tumor cells, some of the mice 
challenged with the OVCAR3/CHI3L1 transfectants $(4 / 8$ for $\mathrm{C} 4$ and 3/8 for C9) showed tumorigenesis. However, none of the mice challenged with OVCAR3 parental cells did (Fig. 6F). With the injection of $1 \times 10^{6}$ or $1 \times 10^{5}$ CA5171/mock cells, four of eight and one of eight mice respectively showed tumorigenesis (Fig. 6G). As also shown in Fig. 6G, none of the mice showed tumorigenesis following injection with $1 \times 10^{6}$ CA5171/CHI3L1-S1 or CA5171/CHI3L1-S2 transfectants (CA5171/CHI3L1knockdown transfectants).

Taken together, these results indicate that CHI3L1 can promote in vivo tumorigenesis by enhancing the quantity of cancer stem-like cells.

\section{Discussion}

We investigated the biological functions of CHI3L1 and if it could be as a potential target in ovarian cancer. Chiang et al. reported that high CHI3L1 correlated with the poor outcome of ovarian cancer (Chiang et al. 2015a). However, the mechanism of CHI3L1 in cancer still needs to be identified. We first identified that ovarian cancer cells could generate spheroids during low-serum culture media. These spheroid cells are more chemoresistant and tumorigenic than their parental cells. Besides, cancer stem-like cells expressed higher CHI3L1 levels than parental cells. Both exogenous and endogenous CHI3L1 could promote the generation of cancer spheroids and properties of ovarian cancer stem-like cells including the expression of ALDH, stemness-related molecules SOX2 and $\beta$-catenin and drug-resistance. CHI3L1 could activate both the Akt (essential) and Erk signaling pathways during the generation of tumor spheroids and cancer stem-like cell properties. The blockade of CHI3L1 and molecules in its related signaling pathway could inhibit tumorigenesis in vivo.

Cancer stem cells play important roles in tumor growth and metastasis (Chabner \& Murphy 2005, Horst et al. 2009, Wakamatsu et al. 2012), and metastasis is an intractable problem in cancer therapy. One hypothesis of cancer metastasis is that cancer stem-like cells separate first from the local tumor site and enter into the circulation as seeds that then land at various distant sites (Bapat et al. 2005, Clevers 2011). However, cancer cells cannot survive for long periods in single cell suspension (Mehlen \& Puisieux 2006, Buchheit et al. 2014), whereas tumor spheroids have proved to be one form in which cancer cells survive longer and circulate within the blood vessels. To form a tumor spheroid, tumor cells need to become cancer stem-like cells (Weiswald et al. 2015), so the quantity of spheroids, including number and size, reflects the numbers of cancer stem-like cells. CHI3L1 promoted the formation of tumor spheroids in our study (Figs 2B and 3C), and earlier results have shown that ovarian cancer patients with the advanced-stage disease have higher CHI3L1 than those with the early stage disease (Weiswald et al. 2015). We hypothesize that ovarian cancer tumors highly expressing CHI3L1 could generate more tumor spheroids, resulting in disease progression and tumor metastasis.

Cancer stem cells also could underlie chemoresistance to cytotoxic drugs in the treatment of ovarian carcinoma (Weiswald et al. 2015). Chemotherapy is always used in metastatic disease, but chemoresistance has been a big challenge, and breaking through it has become a primary focus. Cancer stem-like cells are among the possible explanations for the generation of chemoresistance (Weiswald et al. 2015). Somasagara et al. reported that chemoresistance could be induced by regulating RAD6 gene, which was also associated with the stem cell signaling. RAD6 could activate TLS (PCNA-Ub) and FA/homologous recombination (FANCD2-Ub) to protect ovarian cancer cells from DNA damage caused by chemotherapy (Somasagara et al. 2017).

Patients with chemoresistance are reported to have higher CHI3L1 than those whose cancers are chemosensitive (e.g., in ovarian (Chiang et al. 2015a), glioblastoma ( $\mathrm{Ku}$ et al. 2011, Weiswald et al. 2015) and lung cancer (Johansen et al. 2004)). CHI3L1 increased chemoresistance in ovarian cancer cells in our previous study and generated chemoresistance by boosting numbers of cancer stem-like cells in the current work (Fig. 5F and G; Chiang et al. 2015a). Thus, CHI3L1 could be a potential target for reversing chemoresistance by reducing the numbers of cancer stem-like cells.

The major challenges of current ovarian cancer treatments are the lack of good prognostic factors, initiation of tumor cells, chemoresistance and high recurrence rate. Cancer stem-like cell correlate with chemoresistance and recurrence (Crea et al. 2009, Ahmed et al. 2010, Steg et al. 2012, Jung et al. 2016, Pylväs-Eerola et al. 2016) and CHI3L1 is highly expressed in several human malignancies, including glioblastoma, lung cancer, hepatoma, breast and ovarian cancers (Johansen et al. 2004, Chiba et al. 2006, Park et al. 2010, Ku et al. 2011, Chiang et al. 2015a). Targeting cancer stem cells is an important and novel strategy for cancer therapy. These cells can be tracked through expression of specific surface markers like CD44, CD133 and ALDH (Monzani et al. 2007, Horst et al. 2009, Wakamatsu et al. 2012) 


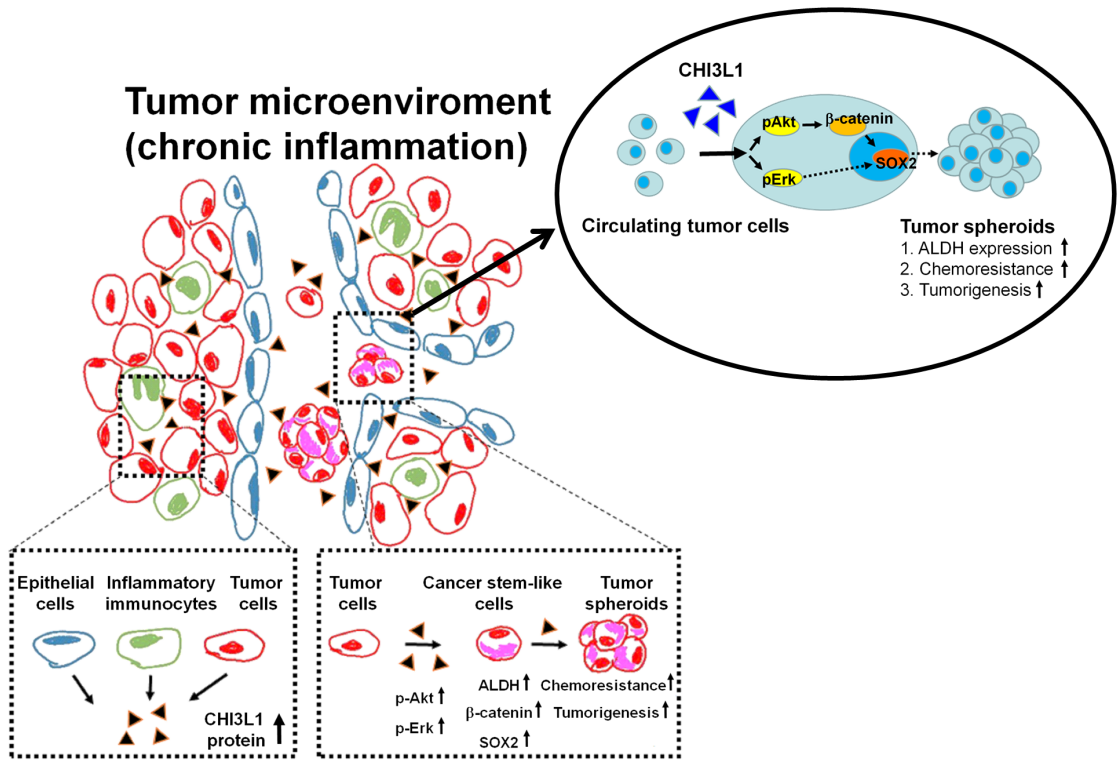

\section{Figure 7}

Schematic of a model of CHI3L1 promotion of tumor spheroid formation and the characteristics of cancer stem-like cells. When ovarian tumors initiate and grow, chronic inflammation arises in the tumor microenvironment. Cancer cells and/or inflammatory cells secrete abundant CHI3L1 in ascites or extracellular matrix. CHI3L1 regulates cancer cells to form tumor spheroids by enhancing expression of stemness-related genes through activation of Akt and Erk signaling pathways. These tumor spheroids then increase chemoresistance and survival of tumor cells, finally migrating to new sites to generate metastasis. A full color version of this figure is available at https://doi.org/10.1530/ERC-18-0300.

through stemness genes such as Nanog, OCT-4 and SOX2 (Kitamura et al. 2013, Almozyan et al. 2017, Lee et al. 2017) or by the unique pattern of staining with certain dyes such as Hoechst 33342 (Goodell et al. 1996). SOX2 and $\beta$-catenin are two intermediate molecules to target in cancer stem-like cells by blocking the function of CHI3L1. Targeting the downstream molecules of CHI3L1 can be another strategy for inhibiting the formation of cancer stemlike cells. SOX2 and $\beta$-catenin were intermediate molecules in CHI3L1-regulated cancer stem-like cell formation in our study (Fig. 6B). Our results showed that blocking phosphor-Akt could suppress the expression level of SOX2 or $\beta$-catenin and impair spheroid formation in single cancer cell suspension. The major functions of SOX 2 and $\beta$-catenin in generating spheroids, however, still need further study. The downstream pathway of SOX2 or $\beta$-catenin may offer more specific and novel targets for ovarian cancer therapy, as has already been discerned in other cancers (GarrosRegulez et al. 2016, Hwang et al. 2016). Recently, the CHI3L1 neutralization antibody, mAY, was shown to confer antiangiogenic properties and promote apoptosis by inhibiting CHI3L1 (Faibish et al. 2011). He and colleagues reported that IL13Ra is the receptor for CHI3L1, offering IL13Ra another potential target for inhibiting CHI3L1 function (Faibish et al. 2011). Small molecule-based inhibition of the Akt or Erk pathway may be another strategy for impairing the function of CHI3L1. Further studies are needed to investigate these possibilities.

Figure 7 illustrates a hypothesized pathway based on our findings in this and our previous study. When ovarian cancer cells initiate and grow, chronic inflammation arises in the tumor microenvironment. Cancer cells and/or inflammatory cells secrete abundant CHI3L1 in ascites or extracellular matrix. CHI3L1 then regulates cancer cells to form tumor spheroids by the expression of stemness-related $\beta$-catenin and then SOX-2 through activation of the Akt (essential) and Erk signaling pathways. These tumor spheroids then increase chemoresistance and the survival of tumor cells, finally migrating to other sites to establish metastases.

In conclusion, cancer stem-like cells are associated with tumor metastasis, resistance to chemotherapy and radiotherapy and tumor recurrence in many studies (Chabner \& Murphy 2005, Chiba et al. 2006, Crea et al. 2009, Moncharmont et al. 2012, Raghavan et al. 2017). Targeting these cells is thus an important and novel strategy to decrease the possibility of tumor metastasis, chemo- or radioresistance and recurrence and to extend patient survival. Our findings suggest that CHI3L1 and its related axis (CHI3L1- $\beta$-catenin-SOX2) may provide a promising target for the treatment of ovarian cancer.

\section{Supplementary data}

This is linked to the online version of the paper at https://doi.org/10.1530/ ERC-18-0300.

\section{Declaration of interest}

The authors declare that there is no conflict of interest that could be perceived as prejudicing the impartiality of the research reported.

\section{Funding}

This work was supported in part by the $2 \mathrm{nd}$, 3rd and 7th core laboratory facility of the Department of Medical Research of National Taiwan 
University Hospital. This study was granted by the Ministry of Science and Technology of Taiwan (MOST 104-2314-B-002-210, MOST 106-2314-B-002 -191 -MY2, and MOST 106-2314-B-002-194-MY2) and National Taiwan University Hospital (NTUH 105-S3097, 106-N3741, and 107-S3842). The funding agency had no role in study design, data collection and analysis, the decision to publish or the preparation of the manuscript.

\section{References}

Agarwal R \& Kaye SB 2003 Ovarian cancer: strategies for overcoming resistance to chemotherapy. Nature Reviews. Cancer 3 502-516. (https://doi.org/10.1038/nrc1123)

Ahmed N, Abubaker K, Findlay J \& Quinn M 2010 Epithelial mesenchymal transition and cancer stem cell-like phenotypes facilitate chemoresistance in recurrent ovarian cancer. Current Cancer Drug Targets 10 268-278. (https://doi. org/10.2174/156800910791190175)

Almozyan S, Colak D, Mansour F, Alaiya A, Al-Harazi O, Qattan A, Al-Mohanna F, Al-Alwan M \& Ghebeh H 2017 PD-L1 promotes OCT4 and Nanog expression in breast cancer stem cells by sustaining PI3K/AKT pathway activation. International Journal of Cancer 141 1402-1412. (https://doi.org/10.1002/ijc.30834)

Bapat SA, Mali AM, Koppikar CB \& Kurrey NK 2005 Stem and progenitor-like cells contribute to the aggressive behavior of human epithelial ovarian cancer. Cancer Research 65 3025-3029. (https://doi. org/10.1158/0008-5472.CAN-04-3931)

Buchheit CL, Weigel KJ \& Schafer ZT 2014 Cancer cell survival during detachment from the ECM: multiple barriers to tumour progression. Nature Reviews. Cancer 14 632-641. (https://doi.org/10.1038/nrc3789)

Chabner BA \& Murphy MJ Jr 2005 Breast cancer: a tale of two centuries: with implications for understanding cancer metastasis and cancer stem cell biology. Oncologist 10 369. (https://doi.org/10.1634/ theoncologist.10-6-369)

Chiang YC, Chen CA, Chiang CJ, Hsu TH, Lin MC, You SL, Cheng WF \& Lai MS 2013 Trends in incidence and survival outcome of epithelial ovarian cancer: 30-year national population-based registry in Taiwan. Journal of Gynecologic Oncology 24 342-351. (https://doi. org/10.3802/jgo.2013.24.4.342)

Chiang YC, Lin HW, Chang CF, Chang MC, Fu CF, Chen TC, Hsieh SF, Chen CA \& Cheng WF 2015a Overexpression of CHI3L1 is associated with chemoresistance and poor outcome of epithelial ovarian carcinoma. Oncotarget 6 39740-39755. (https://doi. org/10.18632/oncotarget.5469)

Chiang YC, Cheng WF, Chang MC, Lu TP, Kuo KT, Lin HP, Hsieh CY \& Chen CA $2015 b$ Establishment of a new ovarian cancer cell line CA5171. Reproductive Sciences 22 725-734. (https://doi. org/10.1177/1933719114557893)

Chiba T, Kita K, Zheng YW, Yokosuka O, Saisho H, Iwama A, Nakauchi H \& Taniguchi H 2006 Side population purified from hepatocellular carcinoma cells harbors cancer stem cell-like properties. Hepatology 44 240-251. (https://doi.org/10.1002/ hep.21227)

Clevers H 2011 The cancer stem cell: premises, promises and challenges. Nature Medicine 17 313-319. (https://doi.org/10.1038/nm.2304)

Cohen JG, White M, Cruz A \& Farias-Eisner R 2014 In 2014, can we do better than CA125 in the early detection of ovarian cancer? World Journal of Biological Chemistry 5 286-300. (https://doi.org/10.4331/ wjbc.v5.i3.286)

Crea F, Danesi R \& Farrar WL 2009 Cancer stem cell epigenetics and chemoresistance. Epigenomics 1 63-79. (https://doi.org/10.2217/ epi.09.4)

Faibish M, Francescone R, Bentley B, Yan W \& Shao R 2011 A YKL-40neutralizing antibody blocks tumor angiogenesis and progression: a potential therapeutic agent in cancers. Molecular Cancer Therapeutics 10 742-751. (https://doi.org/10.1158/1535-7163.MCT-10-0868)
Garros-Regulez L, Garcia I, Carrasco-Garcia E, Lantero A, Aldaz P, Moreno-Cugnon L, Arrizabalaga O, Undabeitia J, Torres-Bayona S, Villanua J, et al 2016. Targeting SOX2 as a therapeutic strategy in glioblastoma. Frontiers in Oncology 6 222. (https://doi.org/10.3389/ fonc.2016.00222).

Goodell MA, Brose K, Paradis G, Conner AS \& Mulligan RC 1996 Isolation and functional properties of murine hematopoietic stem cells that are replicating in vivo. Journal of Experimental Medicine 183 1797-1806. (https://doi.org/10.1084/jem.183.4.1797)

Hansen JW, Thomsen SF, Porsbjerg C, Rasmussen LM, Harmsen L, Johansen JS \& Backer V 2015 YKL-40 and genetic status of CHI3L1 in a large group of asthmatics. European Clinical Respiratory Journal 2 25117. (https://doi.org/10.3402/ecrj.v2.25117)

Horst D, Scheel SK, Liebmann S, Neumann J, Maatz S, Kirchner T \& Jung A 2009 The cancer stem cell marker CD133 has high prognostic impact but unknown functional relevance for the metastasis of human colon cancer. Journal of Pathology 219 427-434. (https://doi. org/10.1002/path.2597)

Hwang SY, Deng X, Byun S, Lee C, Lee SJ, Suh H, Zhang J, Kang Q, Zhang T, Westover KD, et al. 2016 Direct targeting of beta-catenin by a small molecule stimulates proteasomal degradation and suppresses oncogenic Wnt/beta-catenin signaling. Cell Reports 16 28-36. (https://doi.org/10.1016/j.celrep.2016.05.071)

Johansen JS, Drivsholm L, Price PA \& Christensen IJ 2004 High serum YKL-40 level in patients with small cell lung cancer is related to early death. Lung Cancer 46 333-340. (https://doi.org/10.1016/j. lungcan.2004.05.010)

Jung JG, Shih IM, Park JT, Gerry E, Kim TH, Ayhan A, Handschuh K, Davidson B, Fader AN, Selleri L, et al. 2016 Ovarian cancer chemoresistance relies on the stem cell reprogramming factor PBX1. Cancer Research 76 6351-6361. (https://doi.org/10.1158/0008-5472. CAN-16-0980)

Kazakova M, Batalov A, Deneva T, Mateva N, Kolarov Z \& Sarafian V 2013 Relationship between sonographic parameters and YKL-40 levels in rheumatoid arthritis. Rheumatology International 33 341-346. (https://doi.org/10.1007/s00296-012-2387-3)

Kitamura H, Torigoe T, Hirohashi Y, Asanuma H, Inoue R, Nishida S, Tanaka T, Fukuta F, Masumori N, Sato N, et al. 2013 Prognostic impact of the expression of ALDH1 and SOX2 in urothelial cancer of the upper urinary tract. Modern Pathology 26 117-24 (https://doi. org/10.1038/modpathol.2012.139)

Ku BM, Lee YK, Ryu J, Jeong JY, Choi J, Eun KM, Shin HY, Kim DG, Hwang EM, Yoo JC, et al. 2011 CHI3L1 (YKL-40) is expressed in human gliomas and regulates the invasion, growth and survival of glioma cells. International Journal of Cancer 128 1316-1326. (https:// doi.org/10.1002/ijc.25466)

Lee S, Wottrich S \& Bonavida B 2017 Crosstalks between Raf-kinase inhibitor protein and cancer stem cell transcription factors (Oct4, KLF4, Sox2, Nanog). Tumour Biology 39. (https://doi. org/10.1177/1010428317692253)

Libreros S \& Iragavarapu-Charyulu V 2015 YKL-40/CHI3L1 drives inflammation on the road of tumor progression. Journal of Leukocyte Biology 98 931-936. (https://doi.org/10.1189/jlb.3VMR0415-142R)

Livak KJ \& Schmittgen TD 2001 Analysis of relative gene expression data using real-time quantitative PCR and the 2(-Delta Delta C(T)) Method. Methods 25 402-408. (https://doi.org/10.1006/ meth.2001.1262)

Mehlen P \& Puisieux A 2006 Metastasis: a question of life or death. Nature Reviews. Cancer 6 449-458. (https://doi.org/10.1038/nrc1886)

Moncharmont C, Levy A, Gilormini M, Bertrand G, Chargari C, Alphonse G, Ardail D, Rodriguez-Lafrasse C \& Magné N 2012 Targeting a cornerstone of radiation resistance: cancer stem cell. Cancer Letters 322 139-147. (https://doi.org/10.1016/j. canlet.2012.03.024)

Monzani E, Facchetti F, Galmozzi E, Corsini E, Benetti A, Cavazzin C, Gritti A, Piccinini A, Porro D, Santinami M, et al. 2007 Melanoma 
contains CD133 and ABCG2 positive cells with enhanced tumourigenic potential. European Journal of Cancer 43 935-946. (https://doi.org/10.1016/j.ejca.2007.01.017)

Nagourney RA, Brewer CA, Radecki S, Kidder WA, Sommers BL, Evans SS, Minor DR \& DiSaia PJ 2003 Phase II trial of gemcitabine plus cisplatin repeating doublet therapy in previously treated, relapsed ovarian cancer patients. Gynecologic Oncology 88 35-39. (https://doi.org/10.1006/gyno.2002.6855)

Nakahata K, Uehara S, Nishikawa S, Kawatsu M, Zenitani M, Oue T \& Okuyama H 2015 Aldehyde dehydrogenase 1 (ALDH1) is a potential marker for cancer stem cells in embryonal rhabdomyosarcoma. PLOS ONE 10 e0125454. (doi:10.1371/journal.pone.0125454)

Park SY, Lee HE, Li H, Shipitsin M, Gelman R \& Polyak K 2010 Heterogeneity for stem cell-related markers according to tumor subtype and histologic stage in breast cancer. Clinical Cancer Research 16 876-887. (https://doi.org/10.1158/1078-0432.CCR-09-1532)

Pinke DE, Kalloger SE, Francetic T, Huntsman DG \& Lee JM 2008 The prognostic significance of elongation factor eEF1A2 in ovarian cancer. Gynecologic Oncology 108 561-568. (https://doi.org/10.1016/j. ygyno.2007.11.019)

Prat J \& FIGO Committee on Gynecologic Oncology 2014 Staging classification for cancer of the ovary, fallopian tube, and peritoneum. International Journal of Gynecology and Obstetrics 124 1-5. (https://doi. org/10.1016/j.ijgo.2013.10.001)

Pylväs-Eerola M, Liakka A, Puistola U, Koivunen J \& Karihtala P 2016 Cancer stem cell properties as factors predictive of chemoresistance in Neoadjuvantly-treated patients with ovarian cancer. Anticancer Research 36 3425-3431.

Raghavan S, Mehta P, Ward MR, Bregenzer ME, Fleck EMA, Tan L, McLean K, Buckanovich RJ \& Mehta G 2017 Personalized medicine-based approach to model patterns of chemoresistance and tumor recurrence using ovarian cancer stem cell spheroids. Clinical Cancer Research 23 6934-6945. (https://doi. org/10.1158/1078-0432.CCR-17-0133)

Sato M, Kawana K, Adachi K, Fujimoto A, Yoshida M, Nakamura H, Nishida H, Inoue T, Taguchi A, Takahashi J, et al. 2016 Spheroid cancer stem cells display reprogrammed metabolism and obtain energy by actively running the tricarboxylic acid (TCA) cycle. Oncotarget 7 33297-33305. (https://doi.org/10.18632/oncotarget.8947)
Somasagara RR, Spencer SM, Tripathi K, Clark DW, Mani C, Madeira da Silva L, Scalici J, Kothayer H, Westwell AD, Rocconi RP, et al. 2017 RAD6 promotes DNA repair and stem cell signaling in ovarian cancer and is a promising therapeutic target to prevent and treat acquired chemoresistance. Oncogene 36 6680-6690. (https://doi. org/10.1038/onc.2017.279)

Steg AD, Bevis KS, Katre AA, Ziebarth A, Dobbin ZC, Alvarez RD, Zhang K, Conner M \& Landen CN 2012 Stem cell pathways contribute to clinical chemoresistance in ovarian cancer. Clinical Cancer Research 18 869-881. (https://doi.org/10.1158/1078-0432. CCR-11-2188)

Tang DG, Patrawala L, Calhoun T, Bhatia B, Choy G, SchneiderBroussard R \& Jeter C 2007 Prostate cancer stem/progenitor cells: identification, characterization, and implications. Molecular Carcinogenesis 46 1-14. (https://doi.org/10.1002/mc.20255)

Tanwar MK, Gilbert MR \& Holland EC 2002. Gene expression microarray analysis reveals YKL-40 to be a potential serum marker for malignant character in human glioma. Cancer Research $\mathbf{6 2}$ $4364-4368$

van der Burg ME, Lammes FB, van Putten WL \& Stoter G 1988 Ovarian cancer: the prognostic value of the serum half-life of CA125 during induction chemotherapy. Gynecologic Oncology 30 307-312. (https:// doi.org/10.1016/0090-8258(88)90244-2)

Visvader JE 2011 Cells of origin in cancer. Nature 469 314-322. (https:// doi.org/10.1038/nature09781)

Wakamatsu Y, Sakamoto N, Oo HZ, Naito Y, Uraoka N, Anami K, Sentani K, Oue N \& Yasui W 2012 Expression of cancer stem cell markers ALDH1, CD44 and CD133 in primary tumor and lymph node metastasis of gastric cancer. Pathology International 62 112-9. (https://doi.org/10.1111/j.1440-1827.2011.02760.x)

Weiswald LB, Bellet D \& Dangles-Marie V 2015 Spherical cancer models in tumor biology. Neoplasia 17 1-15. (https://doi.org/10.1016/j. neo.2014.12.004)

Wiley CA, Bissel SJ \& Murdoch GH 2015 Role of CHI3L1 in neuroinflammation. Clinical Immunology 161 354. (https://doi. org/10.1016/j.clim.2015.10.003)

Wu C \& Alman BA 2008 Side population cells in human cancers. Cancer Letters 268 1-9. (https://doi.org/10.1016/j.canlet.2008. 03.048)

Received in final form 9 August 2018

Accepted 13 August 2018

Accepted Preprint published online 18 August 2018 (c) 2019 Society for Endocrinology Published by Bioscientifica Ltd. Printed in Great Britain 